\title{
PepT1 expressed in immune cells has an important role in promoting the immune response during experimentally induced colitis
}

\author{
Saravanan Ayyadurai ${ }^{1}$, Moiz A Charania ${ }^{1}$, Bo Xiao $^{1}$, Emilie Viennois ${ }^{1}$ and Didier Merlin ${ }^{1,2}$
}

We and others have shown that the dipeptide cotransporter PepT1 is expressed in immune cells, including macrophages that are in close contact with the lamina propria of the small and large intestines. In the present study, we used PepT1knockout (KO) mice to explore the role played by PepT1 in immune cells during dextran sodium sulfate (DSS)-induced colitis. DSS treatment caused less severe body weight loss, diminished rectal bleeding, and less diarrhea in PepT1-KO mice than in wild-type (WT) animals. A histological examination of colonic sections revealed that the colonic architecture was less disrupted and the extent of immune cell infiltration into the mucosa and submucosa following DSS treatment was reduced in PepT1-KO mice compared with WT animals. Consistent with these results, the DSS-induced colitis increase in colonic myeloperoxidase activity was significantly less in PepT1-KO mice than in WT littermates. The colonic levels of mRNAs encoding the inflammatory cytokines CXCL1, interleukin (IL)-6, monocyte chemotactic protein-1, IL-12, and interferon- $\gamma$ were significantly lower in DSS-treated PepT1-KO mice than in DSS-treated WT animals. Colonic immune cells from WT had significantly higher level of proinflammatory cytokines then PepT1 KO. In addition, we observed that knocking down the PepT1 expression decreases chemotaxis of immune cells recruited during intestinal inflammation. Antibiotic treatment before DSS-induced colitis eliminated the differential expression of inflammatory cytokines between WT and PepT1-KO mice. In conclusion, PepT1 in immune cells regulates the secretion of proinflammatory cytokines triggered by bacteria and/or bacterial products, and thus has an important role in the induction of colitis. PepT1 may transport small bacterial products, such as muramyl dipeptide and the tripeptide L-Ala-gamma-D-Glu-meso-DAP, into macrophages. These materials may be sensed by members of the nucleotide-binding site-leucine-rich repeat family of intracellular receptors, ultimately resulting in altered homeostasis of the intestinal microbiota.

Laboratory Investigation (2013) 93, 888-899; doi:10.1038/labinvest.2013.77; published online 24 June 2013

KEYWORDS: inflammation; PepT1 KO; siRNA

One of the normal transport functions of gut epithelial cells is the absorption of small peptides from the diet, a process mediated by peptide transport activity. ${ }^{1-3}$ This is achieved by the action of the apical membrane protein, intestinal $\mathrm{H}$-coupled oligonucleotide transporter PepT1 (PepT1), which cotransports peptides with $\mathrm{H}^{+}, 4,5$ The specificity of PepT1 is broad and includes many di- and tri-peptides in addition to various peptide-derived drugs. ${ }^{6-12}$ Interestingly, as we first reported, PepT1 transports the small formylated bacterial peptide fMLP. ${ }^{13,14}$ Since that time, we have shown that other bacterial peptides, including muramyl dipeptide (MDP) and the tripeptide L-Ala-gammaD-Glu-meso-DAP (Tri-DAP) may also be transported by PepT1. ${ }^{15,16}$
PepT1 is highly expressed in epithelial cells of the small intestine, but is expressed poorly or not at all in the colon. ${ }^{17}$ However, PepT1 expression is induced in the colon under conditions of chronic inflammation, such as inflammatory bowel disease (IBD) ${ }^{17}$ a process in which the transcription factor Cdx2 has been shown to have an important role. ${ }^{18,19}$ We and others have demonstrated that PepT1 is also expressed in immune cells, such as macrophages, that are in close contact with the lamina propria of the small and large intestines, ${ }^{20-22}$ where low concentrations of small bacterial-derived peptides are present.

The intracellular accumulation of bacterial products such as Tri-DAP, fMLP, and MDP in the epithelial and immune cells mediated by endogenously expressed PepT1 may trigger

${ }^{1}$ Department of Biology, Center for Diagnostics and Therapeutics, Georgia State University, Atlanta, GA, USA and ${ }^{2}$ Veterans Affairs Medical Center, Decatur, GA, USA Correspondence: Dr S Ayyadurai, PhD, Department of Biology, Center for Diagnostics and Therapeutics, Georgia State University, Po Box 5090, Atlanta, GA 30303, USA. E-mail: sayyadurai@gsu.edu

Received 12 February 2013; revised 2 May 2013; accepted 13 May 2013 
intracellular signals that lead to initiation of intestinal inflammatory responses. ${ }^{13,15,16,23,24}$ Induction of an immune response requires recognition of microorganisms by host receptors, such as fMLP receptors or Toll-like receptors, expressed on immune system cells. ${ }^{25-29}$ Alternatively, receptors belonging to the NBS-LRR (nucleotide-binding site-leucine-rich repeat) family, such as NOD2 (nucleotidebinding oligomerization domain containing 2), are also able to detect specific bacterial compounds, such as MDP, and induce inflammatory responses. ${ }^{30-37}$ Indeed, we have demonstrated that PepT1 transporter activity in the colonic epithelial cells has an important role in determining the intracellular levels of ligands for NOD1 and NOD2, which, in turn, determines the activation level of downstream inflammatory pathways. ${ }^{15,38,39}$

The expression of PepT1 in colonic-associated immune cells (eg, macrophages) in close contact with the lamina propria of the intestine $e^{21,22}$ suggests that, during intestinal inflammation, bacterial di- and tripeptides (eg, MDP and Tri-DAP) may be taken up and subsequently interact with NBS-LRR proteins (eg, NOD1 and NOD2), resulting in the activation of an immune response. In the present study, we used PepT1-knockout (KO) mice to examine the role of PepT1 expression in immune cells during dextran sodium sulfate (DSS)-induced colitis.

\section{MATERIALS AND METHODS}

\section{Genotyping of PepT1-KO Mice}

Our laboratory recently obtained PepT1-KO mice from Deltagen (San Mateo, CA). These mice were backcrossed with WT $(\mathrm{C} 57 \mathrm{BL} / 6)$ animals to have the same genetic background in both the littermates (WT and PepT1 KO). Genomic DNA from tail snips was extracted by using REDExtract-Amp Tissue PCR Kit (Sigma, St Louis, MO) according to the manufacturer's protocol. The following primers and conditions were used for identifying the WT, heterozygous and homozygous PepT1-KO mice: forwards; 5'-AGTGTGGG CTGGTGAGACACGTGT-3', 5'-GGGCCAGCTCATTCCTCC CACTCAT-3'; reverse: 5'-CAGGGGGAGAGAGAAACAGA GTTAG-3'. Specific PCR amplifications for each target gene were obtained using the following conditions: $94^{\circ} \mathrm{C}$ for $3 \mathrm{~min}, 94^{\circ} \mathrm{C}$ for $15 \mathrm{~s}, 55^{\circ} \mathrm{C}$ for $30 \mathrm{~s}, 72^{\circ} \mathrm{C}$ for $1 \mathrm{~min}$, and $72{ }^{\circ} \mathrm{C}$ for 10 min with a total of 40 cycles.

\section{Induction of Colitis}

Six-week-old PepT1-KO and C57BL/6 WT female mice were used in the study. Colitis was induced by the addition of $2.5 \%$ (w/v) DSS (molecular weight 36000-50 000 Da; MP Biomedicals, LLC, $\mathrm{OH}$ ) in the drinking water for 7 days. Physical characteristics such as body weight were measured for 7 days. The mice were humanely euthanized, and colon tissue was processed further by extracting total RNA for inflammatory cytokines analysis and immunohistochemistry after 7 days with or without DSS treatment.

\section{Recovery Study}

To assess the recovery of animals from intestinal injury, 6-week-old PepT1-KO and C57BL/6 WT female mice were given 2.5\% DSS for 7 days, and the DSS were replaced with normal drinking water. The recovery from the tissue injury caused by DSS treatment was checked by body weight every day for 7 days. Mice that lost more than 20\% of their body weight from each group was humanely euthanized and noted as dead or not recovered from the tissue injury. Each group had a total of 10 mice with appropriate controls (mice given normal drinking water) were maintained throughout the study. The mice were humanely euthanized and the colonic inflammation was assessed.

\section{Myeloperoxidase Assay}

For myeloperoxidase (MPO) assay, $1 \mathrm{~g}$ of colon tissue was homogenized in $50 \mathrm{mM}$ phosphate buffer ( $\mathrm{pH}$ 6.0) containing $0.5 \%$ hexadecyltrimethyl ammonium bromide (Sigma). The homogenate was sonicated, freeze-thawed three times, and centrifuged at 13000 r.p.m. for $15 \mathrm{~min}$. Supernatant (20 $\mu \mathrm{l})$ was added to $1 \mathrm{mg} / \mathrm{ml}$ o-dianisidine hydrochloride (Sigma) and $0.0005 \% \mathrm{H}_{2} \mathrm{O}_{2}$, and the change in absorbance at $460 \mathrm{~nm}$ was measured.

\section{Endoscopic Assessment of Colitis}

Direct visualization of DSS-induced colonic mucosal damage in vivo was performed using the Coloview (Karl Storz Veterinary Endoscopy, Tuttlingen, Germany). Mice were supplied with food and water until the endoscopy was performed. The mice were anesthetized with 1.5 to $2 \%$ isoflurane, and $3 \mathrm{~cm}$ of the colon proximal to the anus was visualized after inflation of the colon with air. The endoscopic damage score was determined using a previously described scoring method with one modification: assessment of colon translucency ( $0-3$ points), presence of fibrin attached to the bowel wall (0-3 points), granular aspect of the mucosa (0-3 points), morphology of the vascular pattern (0-3 points), and stool characteristic (normal to diarrhea; $0-3$ points). ${ }^{40}$ As this scoring method did not include assessment for the presence of blood in the lumen, we added this parameter (0 points: no blood; 1 point: slight bleeding; and 2 points: frank bleeding) to generate a range in total score from $0-17$ points.

\section{RNA Extraction and Real-Time Reverse Transcription- PCR Analysis}

Total RNA was extracted from the colon of mice by RNeasy Mini kit (Qiagen, Valencia, CA) according to the manufacturer's instruction. The yield and quality of RNA were verified. cDNA was generated from the total RNAs using the maxima first strand cDNA synthesis kit (Thermo Scientific, Glen-Burnie, MD) as described previously. ${ }^{41}$ Levels of inflammatory cytokines were quantified by real-time reverse transcription (RT-PCR) using Maxima SYBR Green/ROX qPCR Master Mix (Fermentas). Fold induction was 
calculated using the $\mathrm{Ct}$ method as follows: $\Delta \Delta \mathrm{Ct}=$ $\left(\mathrm{Ct}_{\text {target }}-\mathrm{Ct}_{\text {housekeeping }}\right)_{\text {group } 1}-\left(\mathrm{Ct}_{\text {target }}-\mathrm{Ct}_{\text {housekeeping }}\right)_{\text {group 2 }}$, and the final data were derived from $2^{-\Delta \Delta \mathrm{CT}}$. Sequence of all primers used for RT-PCR is given in Table 1.

\section{Haematoxylin and Eosin and Immunohistochemistry}

The colon tissues were removed and postfixed by immersion in formalin, embedded in paraffin, sectioned and stained with haematoxylin and eosin. Stained colon tissues sections were observed under a microscope. Scale bars $=50 \mu \mathrm{m}$. For immunestaining, 5- $\mu \mathrm{m}$ paraffin-embedded tissue sections were deparaffinized in xylene, and rehydrated in an ethanol gradient. Epitope retrieval was done by treating tissue sections with $10 \mathrm{mM}$ sodium citrate buffer $(\mathrm{pH} 6.0)$ and $10 \mathrm{~mm}$ citric acid $(116 \mathrm{ml}: 38 \mathrm{ml})$ at $100{ }^{\circ} \mathrm{C}$ for $10 \mathrm{~min}$ in a pressure cooker. Sections were blocked with $10 \%$ goat serum with $1 \%$ BSA in 1X TBS (Tris-buffered saline), and then incubated with Ly6G antibody (neutrophil marker) (1:1000 dilution) overnight at $4{ }^{\circ} \mathrm{C} .{ }^{42}$ After washing in TBS, sections were incubated with $0.3 \% \mathrm{H}_{2} \mathrm{O}_{2}$ and biotinylated goat anti-rat IgG from Vector Labs (Vector Laboratories, Burlingame, CA): Vectastain $A B C$ reaction and $D A B$ reaction (Dako, Carpinteria, CA) were performed subsequently. Slides were counter stained with hematoxylin. Images were acquired using an Olympus microscope equipped with a DP-23 Digital Camera.

\section{Table 1 List of primers used in this study}

\begin{tabular}{|c|c|c|}
\hline No. & Primer & Sequences \\
\hline \multirow[t]{2}{*}{1} & 34B4 sense & 5'-TCCAGGCTITGGGCATCA-3' \\
\hline & 36B4 antisense & 5'-CTIATCAGCTGCACATCACTCAGA-3' \\
\hline \multirow[t]{2}{*}{2} & MCP-1 sense & $5^{\prime}$-CTGGATCGGAACCAAATGAG-3' \\
\hline & MCP-1 antisense & 5'-CGGGTCAACTTCACATTCAA-3' \\
\hline \multirow[t]{2}{*}{3} & IFN- $\gamma$ sense & $5^{\prime}-$ CAGCAACAGCAAGGCGAAA-3' \\
\hline & IFN- $\gamma$ antisense & $5^{\prime}$-CTGGACCTGTGGGTTGTTGAC-3' \\
\hline \multirow[t]{2}{*}{4} & TNF- $\alpha$ sense & 5'-AGGCTGCCCCGACTACGT-3' \\
\hline & TNF- $\alpha$ antisense & 5'-GACTITCTCCTGGTATGAGATAGCAAA-3' \\
\hline \multirow[t]{2}{*}{5} & CXCL-1 sense & 5'-TAGGGTGAGGACATGTGTGG-3' \\
\hline & CXCL-1 antisense & 5'-AAATGTCCAAGGGAAGCGT-3' \\
\hline \multirow[t]{2}{*}{6} & IL-6 sense & 5'-ACAAGTCGGAGGCTTAATTACACAT-3' \\
\hline & IL-6 antisense & $5^{\prime}$-TTGCCATTGCACAACTCTITC-3' \\
\hline \multirow[t]{2}{*}{7} & IL-12 sense & 5'-TACTAGAGAGACTTCTTCCACAACAAGAG-3' \\
\hline & IL-12 antisense & 5'-TCTGGTACATCTTCAAGTCCTCATAGA-3' \\
\hline \multirow[t]{2}{*}{8} & mPepT1 sense & 5'-CTCCATCTTCTACCTGTCCATCAACGCA-3' \\
\hline & mPepT1 antisense & 5'-GCTACGGTTCCTGAAGCGGTIITGACT-3' \\
\hline \multirow[t]{2}{*}{9} & IL-17 sense & $5^{\prime}-C A G G A A C C C T C A T C C T T C A A-3^{\prime}$ \\
\hline & IL-17 antisense & 5'-ATTCCCAAGCCCAGAATCTT-3' \\
\hline \multirow[t]{2}{*}{10} & IL-10 sense & 5'-GGTTGCCAAGCCTTATCGGA-3' \\
\hline & IL-10 antisense & 5'-CTTCTCACCCAGGGAATTCA-3' \\
\hline
\end{tabular}

\section{Ex Vivo and In Vitro Immune Cell Isolation and Cytokine Expression Analysis}

Inflammatory cytokines expression regulated by colonic immune cells of WT and PepT1-KO mice were assessed by isolating the colonic immune cells as previously described. ${ }^{43}$ Collected immune cells resuspended in DMEM media, and the number of cells was counted. Equal numbers of immune cells of WT and PepT1 KO $\left(2.6 \times 10^{7}\right)$ were added on a sixwell plate and stimulated with LPS $(10 \mu \mathrm{g} / \mathrm{ml})$ and incubated at $37^{\circ} \mathrm{C}$ for $1 \mathrm{~h}$, short centrifuged, and washed with phosphate-buffered saline (PBS); and then RNA extracted (Qiagen) for cytokine analysis.

Also, the inflammatory cytokines expression regulated by immune cells, in the presence or absence of PepT1, was assessed in mouse macrophage cell lines (RAW 264.7) by transfecting PepT1 small inhibitory RNA (siRNA) (Ambion, Life Technologies, Grand Island, NY), and later stimulating with LPS for $1 \mathrm{~h}$. RAW 264.7 (mouse macrophage) cells were seeded in 12-well plates at a density of $3.0 \times 10^{6}$ cells/well (Costar, Corning, NY), and incubated at $37^{\circ} \mathrm{C}$ with $5 \% \mathrm{CO}_{2}$ overnight. The transfection of mPepT1 siRNA in macrophages was performed by using Lipofectamine 2000 (Life Technologies) along with a negative and (Ambion) positive control (Ambion) by using the manufacturers protocol. The PepT1 siRNA along with the respective controls at $150 \mu \mathrm{M}$ concentration was used for each transfection, and incubated at $37^{\circ} \mathrm{C}$ with $5 \% \mathrm{CO}_{2}$ for $24 \mathrm{~h}$. The cells were stimulated with LPS for $1 \mathrm{~h}$ and washed with PBS, and RNA extraction and qRT-PCR analysis were performed as described above. The expression of mPepT1 and inflammatory cytokines expression were analyzed with appropriate controls. All transfection studies were done in triplicate, and the experiment was repeated three times.

\section{Quantitative Cell Migration or Chemotaxis Assay}

To analyze the chemotactic cell migration of colonic immune cells of WT and PepT1 KO, equal number of isolated WT and PepT1-KO immune cells $\left(2.6 \times 10^{7}\right)$ were used for the ex vivo chemotaxis assay.

It has been previously shown that RAW 264.7 cells exhibit properties of responsiveness to chemotactic stimuli. ${ }^{44}$ For in vitro analyses, RAW 264.7 cells were plated in DMEM medium containing 10\% FBS without antibiotics on a six-well plate. After $24 \mathrm{~h}$, the $40-50 \%$ confluent wells are transfected with PepT1 siRNA (150 $\mu \mathrm{m} /$ well), Negative control (NC) siRNA $(150 \mu \mathrm{M} /$ well), and nontransfected RAW 264.7 as controls. After $48 \mathrm{~h}$ of transfection, the cells were washed in PBS, scrapped and suspended in DMEM media (without FBS and antibiotics), counted and diluted equally to get $2.6 \times 10^{7}$ cells $/ \mathrm{ml}$.

The chemotaxis assay was performed in a 24 -well cytoselect cell migration assay kit with 5 - $\mu \mathrm{m}$-pore-diameter polycarbonate filter (Cell Biolabs, San Diego, CA). The bottom wells were filled with $500 \mu \mathrm{l}$ of monocyte chemotactic protein-1 (MCP-1) $(250 \mathrm{ng} / \mathrm{ml})$ diluted in DMEM media with 5\% FBS. (Peprotech, Rocky Hill, NJ). In the top wells, immune cells of WT or PepT1 KO or RAW 246.7 cells 
transfected with PepT1 siRNA or NC siRNA or only RAW 246.7 were added. The experiment was done in triplicate. After $24 \mathrm{~h}$ of incubation at $37^{\circ} \mathrm{C}$ and $5 \% \mathrm{CO}_{2}$, the cell migration was assessed by fluorometric format according to the manufacturer's protocol, and read at 480/520 nm in Synergy 2 Multi-Mode Microplate Reader (Biotek, Winooski, VT).

\section{Depletion of Colonic Bacterial Flora by Antibiotic Treatment in WT and PepT1-KO Mice}

It has been previously shown that depleting microbiota in colon significantly reduced the severity of colitis and minimizes the difference of cytokine expression profile upon DSS treatment in mice model. ${ }^{38}$ Hence, the colonic bacteria were removed by treating the mice with antibiotics as previously described. ${ }^{38,45-47} 6$ weeks old female PepT1 KO and C57BL6 WT were given broad spectrum antibiotics $(1 \mathrm{~g} / \mathrm{l})$ in its drinking water for 6 weeks (ampicillin, vancomycin, neomycin sulfate, and metronidazole). After 6 weeks of antibiotic treatment, $2.5 \%$ DSS was given in drinking water for 7 days. Physical characteristics such as body weight were checked every day. Appropriate controls (mice given normal drinking water) were maintained throughout the experiment. The mice were humanely euthanized and colon tissue was collected for cultivable bacteria per gram of tissue. Colonic tissue samples were plated before and after antibiotic treatment to check the depletion of bacteria in colon tissue. Colonic tissues were washed with sterile PBS and $1 \mathrm{~g}$ of tissue was homogenized in $1 \mathrm{ml}$ sterile PBS, and $100 \mu$ l was plated on LB agar and incubated at $37^{\circ} \mathrm{C}$ for $24 \mathrm{~h}$; and then the number of cultivable bacteria were counted and compared with appropriate control groups. Colonic tissues were processed further by extracting total RNA for inflammatory cytokines analysis.

\section{Statistical Analysis}

Values were expressed as means + s.e.m. Statistical analysis was performed using unpaired two-tailed $t$-test by GraphPad Prism 5 software. $P<0.05$ were considered statistically significant.

\section{RESULTS}

\section{Genotyping PepT1-KO Mice}

Heterozygous and homozygous m-PepT1-KO mice were identified using a multiplex RT-PCR strategy. Three reaction steps were used to genotype mice. For both F1 and F2 generations, wild-type (WT) and targeted alleles were detected in multiplex reactions using primers that yielded 213 and 360-bp products, respectively. For F1 mice, a second reaction was performed to detect only the targeted allele (Supplementary Figure a1). Mice positive at this step (targeted allele or heterozygote) were used for further breeding steps (Supplementary Figure a2). For F2 mice, a second reaction was performed to detect only the WT or endogenous allele. These steps ensured that homozygous mutant mice were properly selected (Supplementary Figure a3). Only homozygous mice and their WT littermates were used for further study. The knockdown of PepT1 expression was checked in PepT1-KO mice upon DSS treatment. The small intestine and colon tissue collected for RNA showed no PepT1 expression in PepT1 KO mice compared with WT mice, where PepT1 expression was observed (Supplementary Figure 1b).

\section{Intestinal Inflammation Induced by DSS is Reduced in PepT1-KO Mice}

It has been previously shown that DSS-induced colitis is aggravated in a transgenic mouse line, in which PepT1 is overexpressed in colonic mucosa and normally expressed in immune cells. ${ }^{38}$ Here, we investigated DSS-induced intestinal inflammation in PepT1-KO mice, carrying a germline ablation of PepT1, and in WT mice. As noted in the Introduction, PepT1 is not normally expressed in the colon; thus, PepT1-KO mice lack PepT1 expression in both the colonic mucosa and colonic-associated immune cells, whereas WT mice lack PepT1 expression only in the colonic mucosa. DSS treatment caused less severe body weight loss in PepT1 mice (5\%) compared with WT B/6 mice (15\%), whereas vehicle (water) control mice gained weight (Figure 1a). A colonoscopy performed on day 7 to assess colonic inflammation revealed severe inflammation with bloody diarrhea in the colon of WT mice, whereas PepT1-KO mice exhibited significantly less inflammation and non-bloody diarrhea (Figure 1b). Clinical inflammation scores, based on colonoscopies and assigned as described in Materials and methods, were 13/17 for WT DSS mice and 4/17 for PepT1KO DSS mice (Figure 1c). In addition, a histological examination of colonic sections revealed less disruption of the colonic architecture in PepT1-KO mice upon DSS treatment, with less immune cell infiltration into the mucosa and submucosa (Figure 1d). Consistent with these results, colonic MPO activity, which was increased by DSS treatment in both WT and KO mice, was significantly less in PepT1-KO mice $(0.235 \mathrm{U} / \mathrm{mg})$ than in WT littermates $(0.824 \mathrm{U} / \mathrm{mg}$; Figure $1 \mathrm{e})$.

\section{Neutrophil Infiltration with DSS-Induced Colonic Inflammation in WT and PepT1-KO Mice}

Staining of colon tissue sections with an antibody against Ly6G (a neutrophil marker) showed that the level of neutrophil infiltration following treatment with DSS was significantly higher in WT mice than in PepT1-KO mice (Figure 2a). As expected, neutrophil infiltration was absent in both WT and PepT1-KO vehicle control mice. These results show that the observed increase in colonic MPO activity, described above, is associated with increased neutrophil infiltration in the colonic mucosa, confirming that DSSinduced inflammation is more severe in WT mice than in PepT1-KO mice. The number of infiltrating neutrophil upon DSS treatment was counted microscopically in the colon tissue of WT and PepT1 KO after Ly6G staining. The neutrophil infiltration in WT mice treated with DSS was significantly higher in number than PepT1-KO (Figure 2b). 

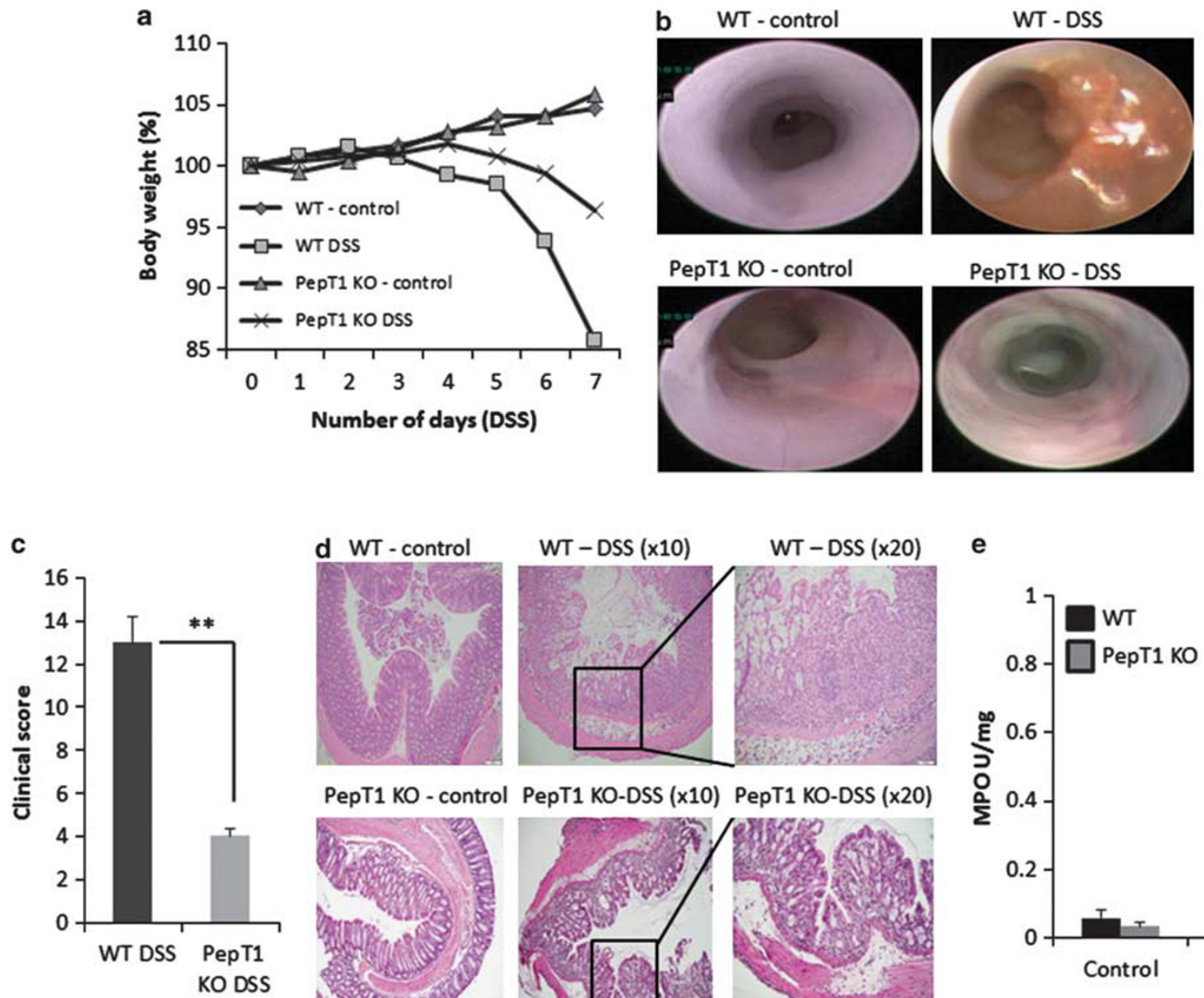

PepT1 KO - control PepT1 KO-DSS (x10) PepT1 KO-DSS (x20)
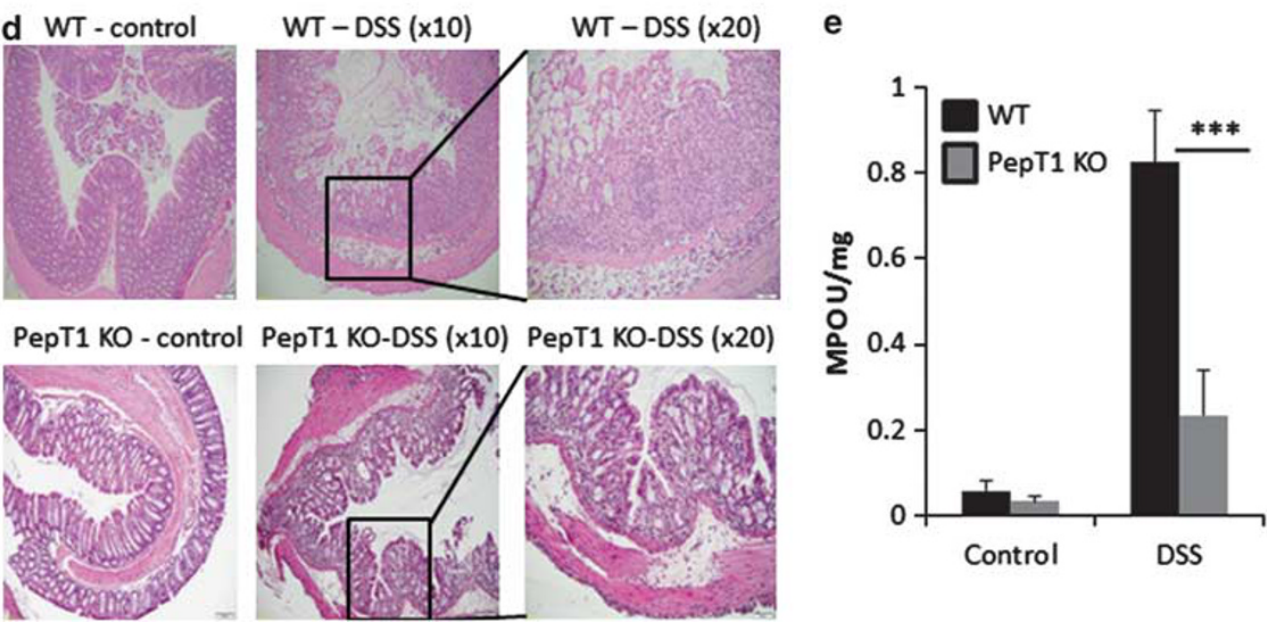

Figure 1 PepT1 deficiency reduces intestinal inflammation induced by DSS in PepT1-KO mice. Body weight of mice exposed to DSS and normal drinking water (a). Colonoscopy performed, to assess colonic inflammation (b). The endoscopic damage score was determined (c). Histological examination of colonic sections of mice experiencing colitis in WT and KO with their respective water controls (d). DSS treatment induced an increase in the colonic activity of MPO in both WT and KO mice (e). Values represent means \pm s.e.m. of $n=6 /$ group. ${ }^{* *} P<0.001$ and ${ }^{* * *} P<0.0001$. Scale bar $=50 \mu \mathrm{m}$.

\section{PepT1 Deficiency Reduces Inflammatory Cytokine Transcriptional Responses in Colonic Cells}

To further investigate the effects of PepT1 ablation on the DSS-induced colonic inflammatory response, we examined changes in the expression of inflammatory cytokines by RT-PCR. The colonic levels of mRNA for the inflammatory cytokines CXCL1 (also known as KC), interleukin (IL)-6, MCP-1, IL-12, interferon (IFN)- $\gamma$, and tumor necrosis factor (TNF) $-\alpha$ in WT mice were significantly increased by DSS compared with $\mathrm{H}_{2} \mathrm{O}$ control (Figure 3), providing additional support for the induction of an inflammatory response in the colonic cells by DSS. The colonic mRNA levels of CXCL1, IL-6, MCP-1, IL-12, and IFN- $\gamma$ were significantly reduced in PepT1-KO mice treated with DSS compared with WT mice treated with DSS. Interestingly, there were no significant differences in TNF- $\alpha$ mRNA levels between WT and PepT1KO mice (Figure 4).

\section{Ex Vivo and In Vitro Analysis of PepT1 Expression In Immune Cells: Contribution of these Cells to the Overall Inflammatory Marker Expression Profile}

Immune cells isolated from WT and PepT1-KO mice were stimulated with LPS, and then RNA was extracted to analyze the mPepT and other inflammatory cytokine expression. As shown in Figure 3, the WT colonic immune cells treated with LPS showed increased expression of mPepT1 compared with PepT1 KO, as it was expected due to knockdown of PepT1. For cytokines such as IL-6, CXCL-1, MCP-1, and IL-10 expression were also significantly higher in WT colonic immune cells compared with PepT1 KO upon LPS treatment (Figure 3). Interestingly, upon LPS treatment, TNF- $\alpha$ expression was also showed statistically significant. Which in contrast during the DSS treatment of the WT and PepT1-KO mice whole colon used for TNF- $\alpha$ cytokine expression (Figure 4). This can be explained by the standard deviation 
a
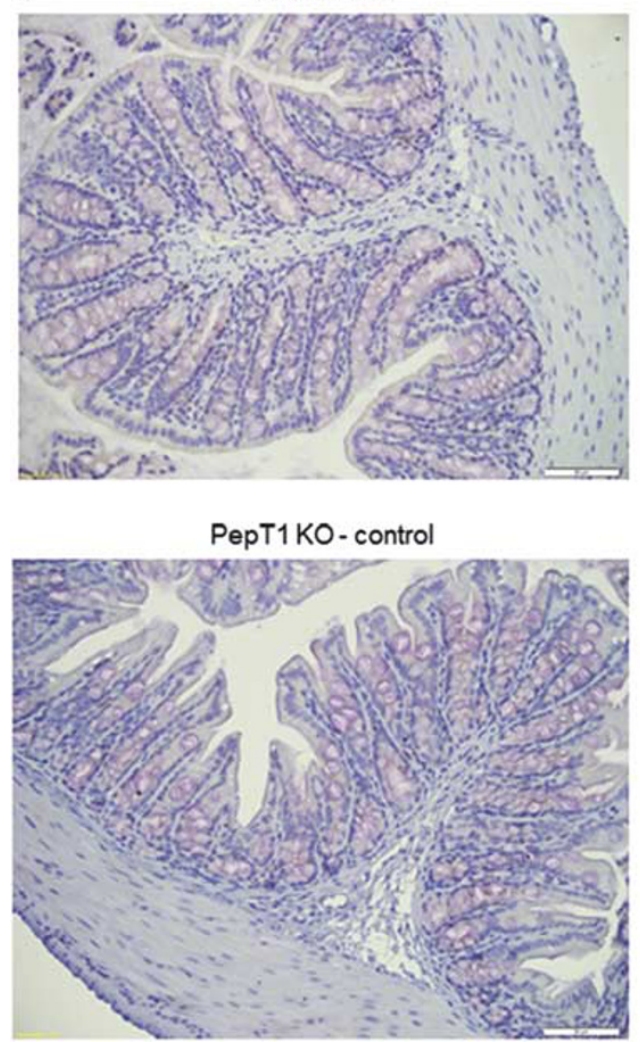
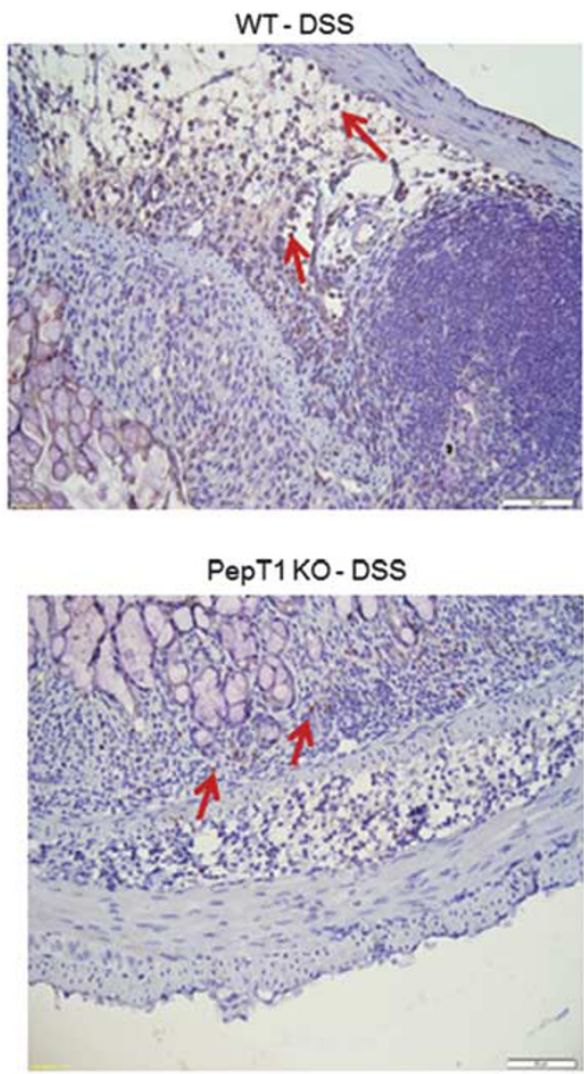

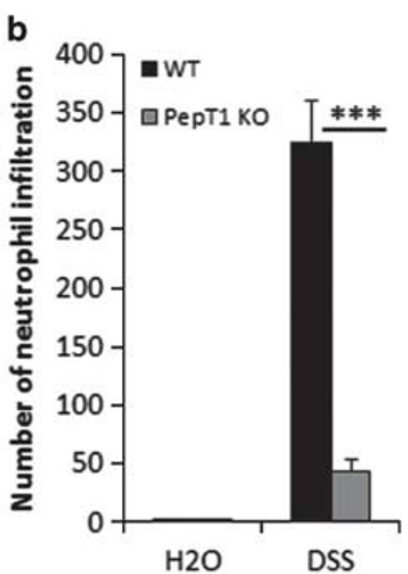

Figure 2 Neutrophil infiltration in DSS-induced colonic inflamed tissues of WT and PepT1-KO mice. Colonic tissue stained with the neutrophil marker (Ly6G) showed no neutrophil infiltration in both WT and PepT1-KO water control mice. Upon DSS treatment, the WT mice had significantly increased levels of neutrophil infiltrations compared with DSS-treated PepT1 deficiency mice (brown colored cells). These results indicate that DSS-induced intestinal inflammation was more severe in WT mice compared with PepT1-KO mice (a). The number of infiltrating neutrophil upon DSS treatment in WT and PepT1-KO mice colon tissue was counted microscopically, and the number of infiltrating neutrophil was shown to be statistically significant (b). Scale bar $=50 \mu \mathrm{m}$.

obtained in the mice study being large in WT mice; hence statistical significance was not obtained.

These results were further confirmed by in vitro analysis of PepT1 expression in the immune cells and their role in inflammatory marker expression profile in the mouse macrophage cell line (RAW 246.7) transfected with siRNA against PepT1 or the appropriate control siRNA. After stimulating siRNA-transfected macrophages with LPS for $1 \mathrm{~h}$, we assessed the expression of PepT1 and other inflammatory markers (cytokines) by qRT-PCR. These results were shown in Supplementary Figure 2. mPepT1 expression was significantly reduced in macrophages transfected with PepT1 siRNA, whereas PepT1 expression was significantly higher in LPS-treated parental macrophages and control macrophages transfected with NC siRNA. Notably, siRNA-mediated downregulation of PepT1 was associated with a significantly diminished induction of CXCL1, TNF- $\alpha$, IL- 6 , and MCP-1 following LPS treatment. Interestingly, the IL-12 cytokine profile remained unchanged (Supplementary Figure 2). On the basis of these ex vivo and in vitro data, we suggest that PepT1 expression in immune cells may contribute to cytokine expression/secretion during intestinal inflammation.

\section{PepT1 Deficiency Decreases Immune Cells Migration Rate and its Possible Role in Immune Cells Mediated Intestinal Inflammation}

Immune cells expressing PepT1 may have relatively higher migration rate towards the tissue injury or inflammation caused by DSS. To test this idea, colonic immune cells from WT and PepT1-KO mice are isolated and the cells were serum starved and chemotaxis assay was performed with equal number of cells. The cells were added on the top and the bottom had a 5\% serum contained DMEM medium with chemoattractants (MCP-1) both the wells were separated by a membrane. As shown in Figure 5 the immune cells isolated from PepT1-KO mice had a reduced rate of migration than immune cells from the WT mice towards the chemoattractants. These results indicate that knockdown of PepT1 expression decreases chemotaxis of colonic immune cells recruited during intestinal inflammation.

To further confirm these results, RAW 246.7 cells were transfected with PepT1 siRNA along with NC siRNA added in to top well were allowed to pass through the membrane towards the DMEM medium (5\% serum) with chemoattractants (MCP-1) in the lower well, which was separated by 

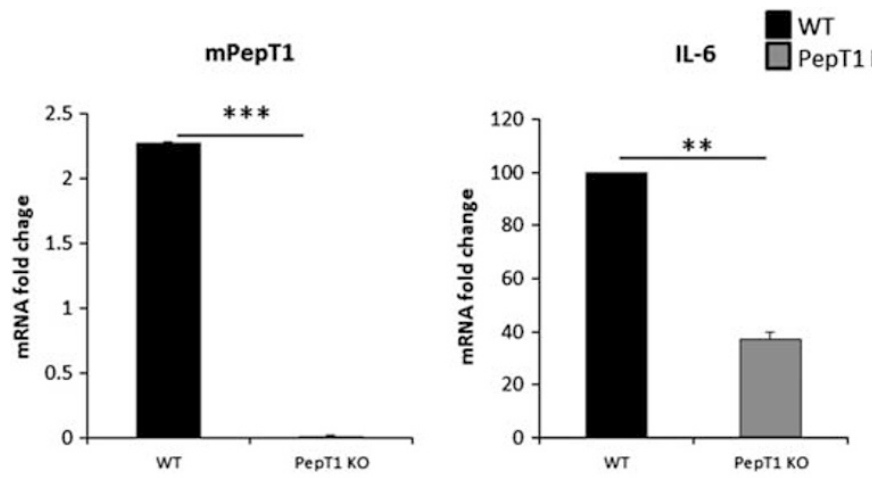

CXCL-1
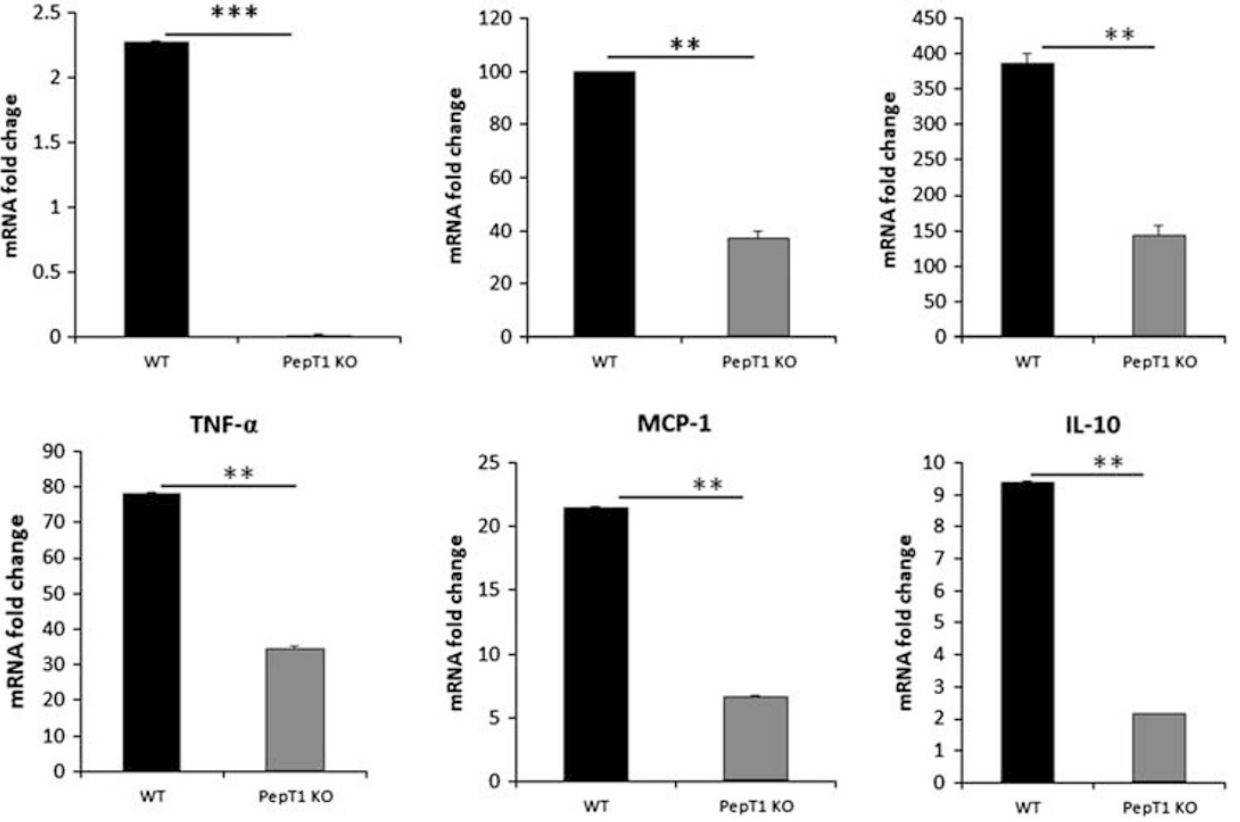

Figure 3. Ex vivo analysis of PepT1 expression in immune cells, and their role in inflammatory markers expression profile. RT-PCR analysis of cytokines expression in the colonic immune cells of WT and PepT1-KO mice stimulated with LPS. The PepT1 expression was significantly more in WT colonic immune cells after LPS treatment, whereas PepT1 KO had no expression of mPepT1. The mRNA expression levels of inflammatory markers such as CXCL1, TNF- $\alpha$, IL-6, MCP-1 and IL-10 were significantly higher in WT colonic immune cells compared with PepT1 KO. Values represent means \pm s.e.m. of $n=3$ and ${ }^{* *} P<0.01,{ }^{* * *} P<0.001$.
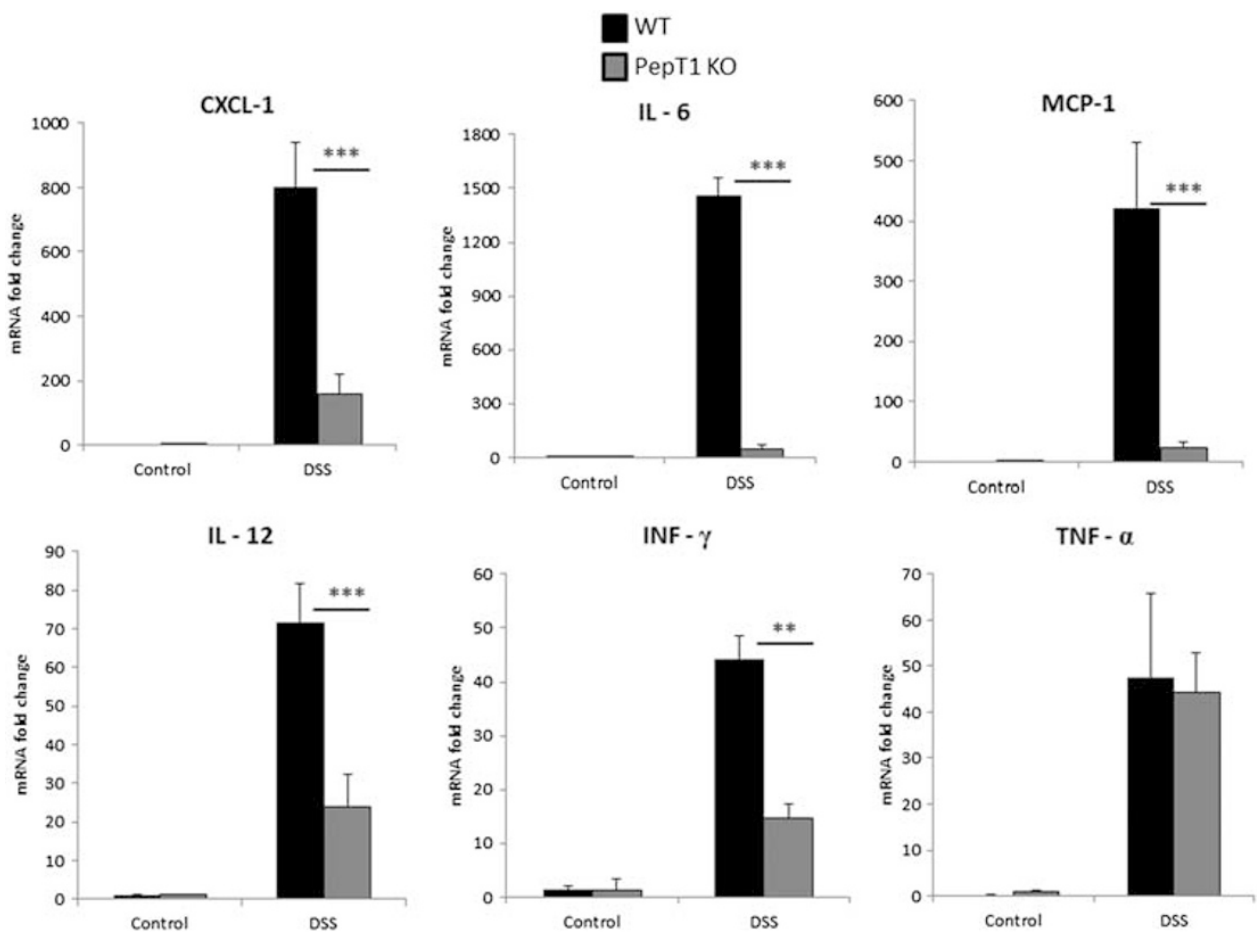

Figure 4. PepT1 deficiency reduces the inflammatory cytokines expression in colonic cells. The colonic mRNA expression levels of inflammatory cytokines IFN- $\gamma$, IL-12, IL-6, TNF- $\alpha$, MCP-1, and CXCL1 were significantly increased in mice treated with DSS compared with water control. The colonic mRNA expression levels of inflammatory cytokines (IFN- $\gamma$, IL-12, IL-6, MCP-1, and CXCL1) were reduced significantly in PepT1-KO mice treated with DSS compared with WT mice treated with DSS. Values represent means \pm s.e.m. of $n=6 /$ group and ${ }^{* *} P<0.001,{ }^{* * *} P<0.0001$. 


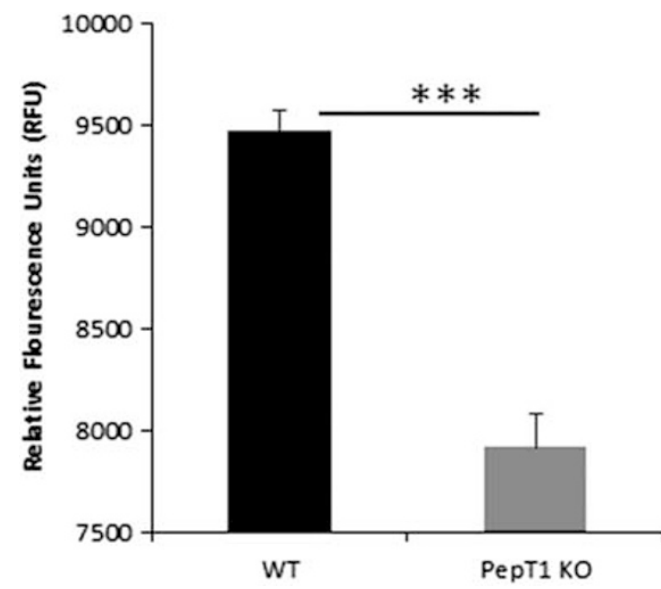

Figure 5 PepT1 deficiency decreases immune cells migration rate and its possible role in immune cells mediated intestinal inflammation. Colonic immune cells of WT and PepT1-KO mice were isolated and chemotaxis assay was performed. The top well had the respective immune cells and the bottom well had $5 \%$ serum containing DMEM medium with chemoattractants (MCP-1). Top and bottom wells were separated by a membrane. After $24 \mathrm{~h}$ of incubation at $37^{\circ} \mathrm{C}$ as shown in this figure the immune cells isolated from PepT1-KO mice had a reduced rate of migration towards the chemoattractants than immune cells from the WT mice. Values represent means \pm s.e.m. of $n=3$ and ${ }^{* * *} P<0.0001$.

$5 \mu \mathrm{M}$ pore size membrane. As shown in Supplementary Figure 3, the PepT1 siRNA transfected macrophages had a reduced rate of migration than the cells transfected with $\mathrm{NC}$ siRNA towards the chemo-attractants. The ex vivo and in vitro results indicate that reduction/knock down of PepT1 expression decreases chemotaxis of immune cells recruited during intestinal inflammation (Supplementary Figure 3).

\section{PepT1 Deficiency Increases the Survival of Mice following DSS-Induced Intestinal Inflammation}

We next examined the effect of PepT1 deficiency in vivo, testing the ability of mice to recover from DSS-induced colitis. Mice were treated with DSS for 7 days, provided in drinking water, after which DSS water was replaced with normal drinking water (recovery phase), and the mice were monitored for 8 days to assess recovery from DSS-induced intestinal injury. During the recovery phase, all WT mice lost more than $20 \%$ of their body weight by day 3 and were killed. In contrast, PepT1-KO animals start to gain weight after day 4 , and recovered $95 \%$ of their initial body weight by day 7 (Figure 6). Taken together, these results show that the absence of PepT1 increases intestinal recovery in mice following DSS-induced colitis.

\section{Antibiotic Treatment Decreases the Colonic Bacterial Population and Reduces the Severity of Colitis in WT and PepT1-Ko Mice}

To determine the amount of cultivable bacteria in the colon of WT and PepT1-KO mice, we humanely euthanized 6-week-old mice and cultured $1 \mathrm{~g}$ of colon tissue on LB media as described in Materials and methods. These experiments

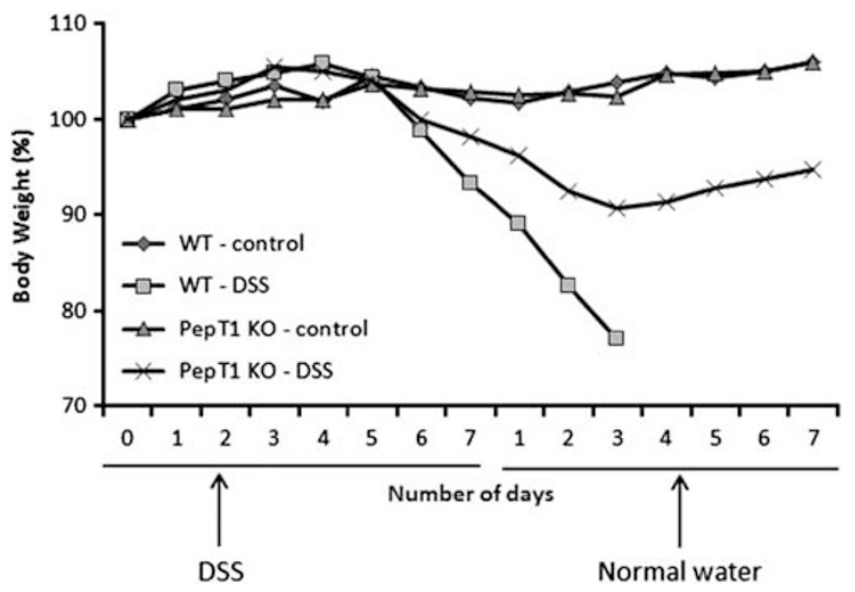

Figure 6 PepT1 deficiency increases the survival from DSS-induced intestinal inflammation. To study the effect of PepT1 deficiency in the ability of mice to recover from DSS-induced colitis, mice were treated with DSS for 7 days, and then DSS water was replaced with normal drinking water (recovery phase), and then the recovery from the DSS-induced intestinal injury was observed for 8 days. $n=10 /$ group.

showed that WT mice had a significantly greater number of cultivable bacteria than PepT1-KO mice (Figure 7a). Both PepT1-KO mice and WT littermates were treated for 6 weeks with broad-spectrum antibiotics given in drinking water to deplete intestinal enteric microbial communities. Three randomly selected WT and PepT1-KO mice were killed, and their colon tissues were dissected. After washing with sterile PBS, $1 \mathrm{~g}$ of colonic tissue was homogenized and $100 \mu \mathrm{l}$ of the homogenate was cultured immediately after antibiotic treatment. The number of cultivable bacteria was quantified and compared with that obtained from mice not treated with antibiotics to confirm bacterial depletion. Antibiotic treatment markedly reduced the total number of bacteria in WT and PepT1-KO mice (Figure 7b).

The remaining antibiotic-treated mice ( $n=7$ /group) were given DSS for 7 days, and intestinal inflammation was assessed and compared with that in vehicle control mice. DSS treatment produced a mild effect on both WT and PepT1-KO mice, reducing body weight by $9 \%$ in WT mice and $7 \%$ in PepT1-KO mice (Figure 8c). Mice in both control groups showed an increase (3-4\%) in body weight at the end of the experiment (Figure 7c).

These results demonstrate that antibiotic treatment markedly reduced the total number of cultivable bacteria in both WT and PepT1-KO mice, and eliminated the differential effects of DSS-induced colitis in WT and PepT1-KO mice. Collectively, these results suggest that bacteria has an important role in the observed aggravation of DSS-induced colitis in WT mice compared with PepT1-KO mice.

Antibiotic Treatment Eliminates the Differential Expression of Inflammatory Cytokines in WT and PepT1-KO Mice

Measurements of inflammatory cytokine mRNA levels confirmed that DSS induced a mild colonic inflammation in 
a

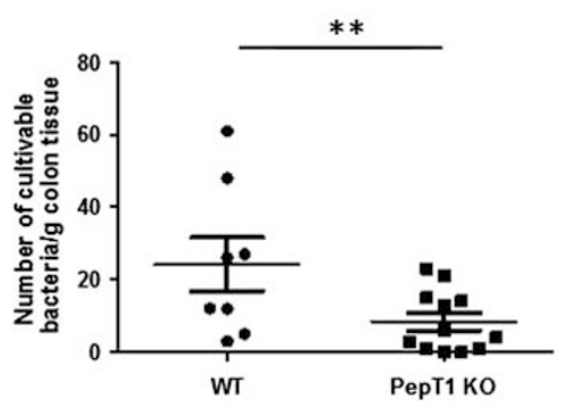

C

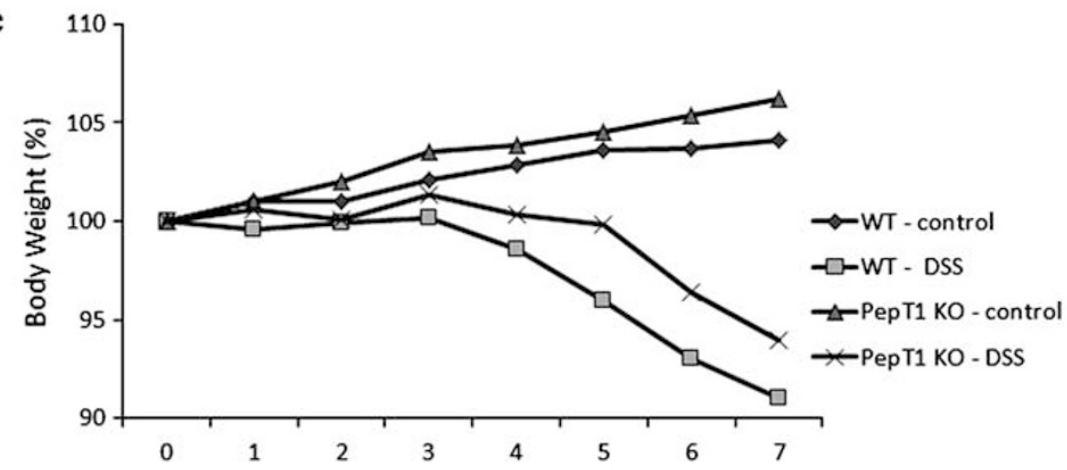

Number of days-DSS (prior 6 weeks antibiotics treated)

Figure 7 Broad-spectrum antibiotic treatment decreases the colonic bacterial population and reduces the severity of colitis in WT and PepT1-KO mice. The amount of cultivable bacteria in the colon of WT and PepT1-KO mice (a). Both the WT and PepT1-KO littermates were treated for 6 weeks with broad-spectrum antibiotics given in drinking water to deplete enteric microbial communities in the intestine. Three randomly selected WT and PepT1$\mathrm{KO}$ mice were killed and the numbers of cultivable bacteria were quantified (b). Six weeks antibiotic treated mice were given DSS for 7 days, and the intestinal inflammation was assessed by body weight (c). Values represent means \pm s.e.m. of $n=7 /$ group and ${ }^{* *} P<0.001$.

- WT DSS

口 PepT1 KO DSS

IFN $\gamma$

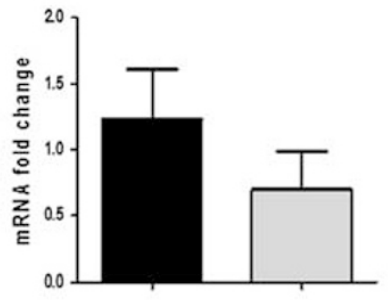

CXCL-1

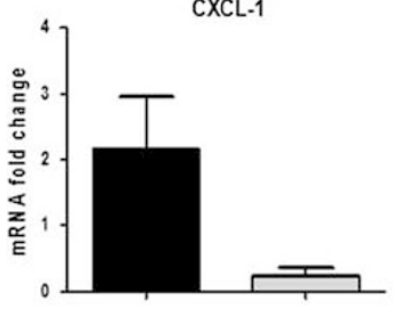

IL-12

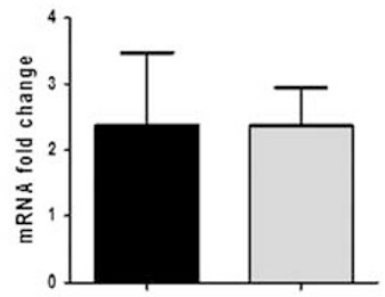

TNF- $\alpha$

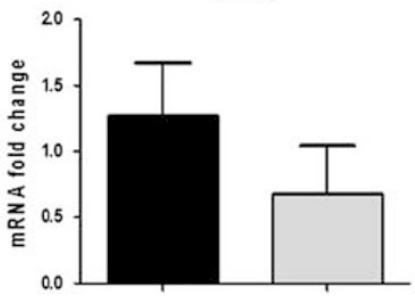

IL.6

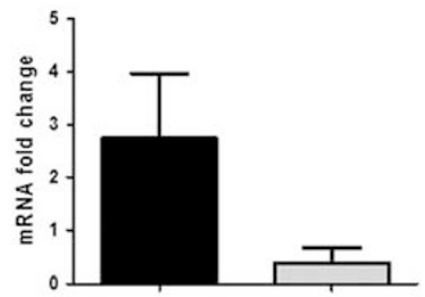

IL-1 $\beta$

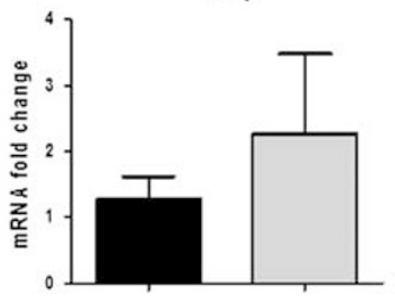

Figure 8 Antibiotics treatment eliminates the differential expression of inflammatory cytokines in WT and PepT1-KO mice. After 6 weeks of antibiotic treatment, mice exposed to DSS had mild colonic inflammation, with no significant difference evident between WT and PepT1-KO mice, as assessed by measuring the expression levels of proinflammatory cytokines. IFN- $\gamma$, IL-12, IL-6, CXCL1, TNF- $\alpha$, and IL- $1 \beta$ expressions were lower in antibiotic + DSStreated WT and PepT1-KO mice. Antibiotic treatment eliminated the difference in cytokine mRNA levels between WT and PepT1-KO mice. Values represent means \pm s.e.m. of $n=7 /$ group. 
antibiotic-treated mice compared with that in untreated mice (Figure 8). DSS-treated WT and PepT1-KO mice given antibiotics showed no significant difference in the expression of the proinflammatory cytokines CXCL1, IL-12, IFN- $\gamma$, TNF- $\alpha$, and IL-1 $\beta$ (Figure 8). Thus, antibiotic treatment eliminated the difference in cytokine mRNA levels between WT and PepT1-KO mice. Interestingly, in contrast to WT mice after antibiotic treatment, the increase in IL- 6 and IL-12 induced by DSS was not significantly different between DSS-treated and untreated PepT1-KO mice after antibiotic treatment (Figure 8). Results from control mice given normal drinking water, which expressed a similar cytokine profile (Figure 4), are not included in these data. Taken together, these results suggest that the role of bacteria in intestinal inflammation, noted above, is due, at least in part, to PepT1 expression.

\section{DISCUSSION}

The present study extends the findings of our previous studies, which showed that bacterial products such as fMLP, Tri-DAP, and MDP may be transported by the intestinal epithelial oligopeptide transporter, PepT1. ${ }^{13-16}$ Once in the cytosol, these small bacterial peptides initiate an inflammatory response. ${ }^{13,15,16,23,24}$ Inflamed colonocytes express PepT1 and, consequently, have the capacity to take up such bacterial peptides, which can subsequently interact with members of the NBS-LRR family of intracellular receptors (eg, NOD1/NOD2) that mediate intracellular recognition of microbes and their products. ${ }^{30-37}$ Thus, an inflammatory response initiated at the epithelial level could lead to an inflammatory cascade that results in tissue damage. ${ }^{15,38,39}$ In addition, we have previously demonstrated that PepT1 is also expressed in immune cells and may transport small proinflammatory peptides such as fMLP, thereby participating in the intestinal inflammatory responses. ${ }^{20-22,48}$ Importantly, it has recently been shown that a PepT1 polymorphism is associated with IBD. Overall, our studies have revealed that PepT1 may be involved in the pathogenesis of IBD in humans. ${ }^{17,49,50}$ However, a direct role of PepT1 in immune cells during intestinal inflammation has not been investigated.

In the present study, we used PepT1-KO mice, ${ }^{51-54}$ in which PepT1 is not expressed in colonic epithelial or immune cells, and WT mice, in which PepT1 is expressed in immune cells but not in colonic epithelial cells. First, we observed that DSS-induced colitis was less severe in PepT1-KO mice compare with WT mice. Our results suggested that this difference could be explained by the modest elevation in the expression of proinflammatory cytokines (eg, CXCL1, IL-6, MCP-1, IL-12, and INF- $\gamma$ ) in PepT1-KO mice compared with WT mice after DSS treatment. As immune cells are the primary source of secreted proinflammatory cytokines, we hypothesized that the lack of PepT1 expression in the immune cells of PepT1-KO mice could affect the production of proinflammatory cytokines by these cells. Indeed, we also demonstrated that inflamed macrophages lacking PepT1 expression secreted less cytokine than the same macrophages expressing PepT1. This suggests that immune cells that express the PepT1 transporter may directly utilize di- and tri peptides. Moreover, the expression of PepT1 in immune cells may provide the supply of small peptides needed for the secretion of cytokines and chemokine receptor(s) involved in intestinal inflammation. In this context, it is possible that the expression of chemokine receptor(s) could be decreased in immune cells with low PepT1 expression. Indeed, we observed that reduction of PepT1 expression decreases chemotaxis of immune cells recruited during intestinal inflammation. Further support for this latter conclusion may be provided by the observation that small peptides (eg, arginine-containing peptides) taken up by the PepT1 transporter system can serve as direct substrates of inducible nitric oxide (NO) synthase in the production of NO by alveolar macrophages. ${ }^{55}$ Other studies have demonstrated that some membrane channel activities in macrophages are important in IL- $1 \beta$ secretion via regulation of the Nlrp3 (NACHT/LRR/pyrin domain-containing protein 3) inflammasome. ${ }^{56}$ In addition, we have demonstrated that wound healing is improved in PepT1KO mice compared with WT mice. This latter observation suggests that wounds induced by DSS resolve themselves more effectively in PepT1-KO mice, resulting in less severe colonic tissue damage.

We further explored the role of colonic bacteria in PepT1mediated inflammation by treating PepT1-KO mice and WT littermates treated for 6 weeks with broad-spectrum antibiotics to deplete enteric microbial communities before the induction of colitis with DSS. An assessment of various parameters of colitis and inflammation, including inflammatory cytokine levels, in these mice showed that antibiotic treatment eliminated the difference in colitis severity between WT and PepT1-KO mice. These results suggest that bacteria and/or bacterial products, such as fMLP, MDP and/ or Tri-DAP, are crucial for aggravation of DSS-induced colitis in WT animals. Interestingly, colonic bacterial levels were higher in WT mice than in PepT1-KO mice, possibly suggesting that some distinct bacterial population not present in PepT1-KO mice which is induced by the absence of PepT1 expression in colonic immune cells. Colonic immune cells, such as dendritic cells and macrophages, are instrumental in maintaining immune homeostasis and tolerance in the gut and in controlling intestinal inflammation. Colonic immune cells lacking PepT1 expression could affect interactions between intestinal microbiota and the innate immune system, providing a possible explanation for the lower numbers of colonic bacteria in PepT1-KO mice. It is also possible that bacterial products that are transported by PepT1 are not taken up by immune cells in PepT1-KO mice, inducing dysregulation of bacterial recognition. This would prevent immune cells such as macrophages from sensing bacterial products through the NBS-LRR family of intracellular receptors that are expressed in macrophages, ultimately affecting overall colonic bacterial homeostasis. 
We previously demonstrated the contribution of mucosal versus immune cell-derived hPepT1 to the development of colitis. ${ }^{38}$ We generated bone marrow chimeras of WT mice or $\beta$-actin-hPepT1 mice (ubiquitously overexpressing hPepT1). WT mice that received myeloid cells from $\beta$-actin-hPepT1 animals overexpressed hPepT1, whereas WT mice that received myeloid cells from WT mice showed normal PepT1 expression. We found that the former were more sensitive to induced colitis than the latter. As the two groups differed only in the expression level of PepT1 in their immune cells, we concluded that PepT1 expression in immune cells has a role in the proinflammatory response. ${ }^{38}$ In this study, PepT1 was not detected in IECs from WT or PepT1-KO mice, but its expression differed in the immune cells of WT mice (detectable PepT1 expression) and PepT1KO mice (no detectable PepT1 expression), which suggest that the observed effects are likely due to differences in the PepT1 expression levels of their immune cells.

In the present study, we have demonstrated that PepT1 expression in immune cells plays an important role in DSSinduced colitis. PepT1 expressed in immune cells regulates proinflammatory cytokine secretion, which is dependent on bacteria and/or bacterial products. Immune cell PepT1 may thus serve to transport small bacterial products such as MDP and tri-DAP into macrophages, allowing them to be sensed by the NBS-LRR family of intracellular receptors and participate in intestinal microbiota homeostasis.

Supplementary Information accompanies the paper on the Laboratory Investigation website (http://www.laboratoryinvestigation.org)

\section{ACKNOWLEDGEMENTS}

This work was supported by grants from the Department of Veterans Affairs (to DM). We dedicate this article to the memory of Dr Shanthi V Sitaraman, a brilliant scientist, dedicated physician, passionate humanitarian and dearest friend.

\section{DISCLOSURE/CONFLICT OF INTEREST}

The authors declare no conflict of interest.

1. Adibi SA. Intestinal transport of dipeptides in man: relative importance of hydrolysis and intact absorption. J Clin Invest 1971;50:2266-2275.

2. Mathews DM, Adibi SA. Peptide absorption. Gastroenterology 1976; 71:151-161.

3. Adibi SA. Regulation of expression of the intestinal oligopeptide transporter (Pept-1) in health and disease. Am J Physiol Gastrointest Liver Physiol 2003;285:G779-G788.

4. Fei YJ, Kanai Y, Nussberger $S$, et al. Expression cloning of a mammalian proton-coupled oligopeptide transporter. Nature 1994;368:563-566.

5. Liang $\mathrm{R}$, Fei $\mathrm{YJ}$, Prasad PD, et al. Human intestinal $\mathrm{H}+$ /peptide cotransporter. Cloning, functional expression, and chromosomal localization. J Biol Chem 1995;270:6456-6463.

6. Bretschneider B, Brandsch M, Neubert R. Intestinal transport of betalactam antibiotics: analysis of the affinity at the $\mathrm{H}+/$ peptide symporter (PEPT1), the uptake into Caco-2 cell monolayers and the transepithelial flux. Pharm Res 1999;16:55-61.

7. Brodin B, Nielsen CU, Steffansen B, et al. Transport of peptidomimetic drugs by the intestinal Di/tri-peptide transporter, PepT1. Pharmacol Toxicol 2002;90:285-296.
8. de Vrueh RL, Smith PL, Lee CP. Transport of L-valine-acyclovir via the oligopeptide transporter in the human intestinal cell line, Caco-2. J Pharmacol Exp Ther 1998;286:1166-1170.

9. Friedman DI, Amidon GL. Intestinal absorption mechanism of dipeptide angiotensin converting enzyme inhibitors of the lysylproline type: lisinopril and SQ 29,852. J Pharm Sci 1989;78:995-998.

10. Kramer W, Girbig F, Gutjahr U, et al. Interaction of renin inhibitors with the intestinal uptake system for oligopeptides and beta-lactam antibiotics. Biochim Biophys Acta 1990;1027:25-30.

11. Nielsen CU, Supuran CT, Scozzafava A, et al. Transport characteristics of L-carnosine and the anticancer derivative 4-toluenesulfonylureidocarnosine in a human epithelial cell line. Pharm Res 2002;19: 1337-1344.

12. Daniel H. Molecular and integrative physiology of intestinal peptide transport. Annu Rev Physiol 2004;66:361-384.

13. Merlin D, Steel A, Gewirtz AT, et al. hPepT1-mediated epithelial transport of bacteria-derived chemotactic peptides enhances neutrophil-epithelial interactions. J Clin Invest 1998;102:2011-2018.

14. Buyse $M$, Charrier L, Sitaraman $S$, et al. Interferon-gamma increases hPepT1-mediated uptake of di-tripeptides including the bacterial tripeptide fMLP in polarized intestinal epithelia. Am J Pathol 2003;163:1969-1977.

15. Vavricka SR, Musch MW, Chang JE, et al. hPepT1 transports muramyl dipeptide, activating NF-kappaB and stimulating IL-8 secretion in human colonic Caco2/bbe cells. Gastroenterology 2004;127: 1401-1409.

16. Dalmasso G, Nguyen HT, Charrier-Hisamuddin L, et al. PepT1 mediates transport of the proinflammatory bacterial tripeptide L-Ala-\{gamma\}D-Glu-meso-DAP in intestinal epithelial cells. Am J Physiol Gastrointest Liver Physiol 2010;299:G687-G696

17. Merlin D, Si-Tahar M, Sitaraman SV, et al. Colonic epithelial hPepT1 expression occurs in inflammatory bowel disease: transport of bacterial peptides influences expression of MHC class 1 molecules. Gastroenterology 2001;120:1666-1679.

18. Nguyen HT, Dalmasso G, Powell KR, et al. Pathogenic bacteria induce colonic PepT1 expression: an implication in host defense response. Gastroenterology 2009;137:1435-47, e1-2.

19. Nduati V, Yan Y, Dalmasso G, et al. Leptin transcriptionally enhances peptide transporter (hPepT1) expression and activity via the CAMPresponse element-binding protein and $\mathrm{Cdx} 2$ transcription factors. J Biol Chem 2007;282:1359-1373.

20. Charrier L, Merlin D. The oligopeptide transporter hPepT1: gateway to the innate immune response. Lab Invest 2006;86:538-546.

21. Smith PD, Smythies LE, Mosteller-Barnum $M$, et al. Intestinal macrophages lack CD14 and CD89 and consequently are downregulated for LPS- and IgA-mediated activities. J Immunol 2001;167: 2651-2656.

22. Smythies LE, Sellers $M$, Clements $R H$, et al. Human intestina macrophages display profound inflammatory anergy despite avid phagocytic and bacteriocidal activity. J Clin Invest 2005;115:66-75.

23. Buyse M, Tsocas A, Walker F, et al. PepT1-mediated fMLP transport induces intestinal inflammation in vivo. Am J Physiol Cell Physiol 2002;283:C1795-C1800.

24. Chiu NM, Chun T, Fay $M$, et al. The majority of $\mathrm{H}_{2}-\mathrm{M} 3$ is retained intracellularly in a peptide-receptive state and traffics to the cell surface in the presence of N-formylated peptides. J Exp Med 1999; 190:423-434.

25. Le Y, Murphy PM, Wang JM. Formyl-peptide receptors revisited. Trends Immunol 2002;23:541-548.

26. Eckmann L. Innate immunity and mucosal bacterial interactions in the intestine. Curr Opin Gastroenterol 2004;20:82-88.

27. Eckmann L. Sensor molecules in intestinal innate immunity against bacterial infections. Curr Opin Gastroenterol 2006;22:95-101.

28. Philpott DJ, Girardin SE. The role of Toll-like receptors and Nod proteins in bacterial infection. Mol Immunol 2004;41:1099-1108.

29. Ku CL, Yang K, Bustamante J, et al. Inherited disorders of human Tolllike receptor signaling: immunological implications. Immunol Rev 2005;203:10-20.

30. Chamaillard M, Girardin SE, Viala J, et al. Nods, Nalps and Naip: intracellular regulators of bacterial-induced inflammation. Cell Microbiol 2003;5:581-592.

31. Barnich N, Aguirre JE, Reinecker $\mathrm{HC}$, et al. Membrane recruitment of NOD2 in intestinal epithelial cells is essential for nuclear 
factor-\{kappa\}B activation in muramyl dipeptide recognition. J Cell Biol 2005;170:21-26.

32. Inohara Chamaillard, McDonald C, Nunez G. NOD-LRR proteins: role in host-microbial interactions and inflammatory disease. Ann RevBiochem 2005;74:355-383.

33. Inohara N, Nunez G. NODs: intracellular proteins involved in inflammation and apoptosis. Nat Revlmmunol 2003;3:371-382.

34. Murillo LS, Morre SA, Pena AS. Toll-like receptors and NOD/CARD proteins: pattern recognition receptors are key elements in the regulation of immune response. Drugs Today 2003;39:415-438.

35. Strober W, Murray PJ, Kitani A, et al. Signalling pathways and molecular interactions of NOD1 and NOD2. Nat Rev Immunol 2006; 6:9-20.

36. Tanabe $\mathrm{T}$, Chamaillard M, Ogura $\mathrm{Y}$, et al. Regulatory regions and critical residues of NOD2 involved in muramyl dipeptide recognition. EMBO J 2004:23:1587-1597.

37. Viala J, Sansonetti $P$, Philpott DJ. Nods and 'intracellular' innate immunity. C R Biol 2004;327:551-555.

38. Dalmasso G, Nguyen HT, Ingersoll SA, et al. The PepT1-NOD2 signaling pathway aggravates induced colitis in mice. Gastroenterology 2011; 141:1334-1345

39. Laroui H, Yan Y, Narui Y, et al. L-Ala-gamma-D-Glu-meso-diaminopimelic acid (DAP) interacts directly with leucine-rich region domain of nucleotide-binding oligomerization domain 1 , increasing phosphorylation activity of receptor-interacting serine/threonine-protein kinase 2 and its interaction with nucleotide-binding oligomerization domain 1. J Biol Chem 2011:286:31003-31013.

40. Cooper HS, Murthy SN, Shah RS, et al. Clinicopathologic study of dextran sulfate sodium experimental murine colitis. Lab Invest 1993;69:238-249.

41. Charania MA, Ayyadurai S, Ingersoll SA, et al. Intestinal epithelial CD98 synthesis specifically modulates expression of colonic microRNAs during colitis. Am J Physiol Gastrointest Liver Physiol 2012;302: G1282-G1291.

42. Charania MA, Laroui $\mathrm{H}$, Liu $\mathrm{H}$, et al. Intestinal epithelial CD98 directly modulates the innate host response to enteric bacterial pathogens. Infect Immun 2013;81:923-934.

43. Weigmann B, Tubbe I, Seidel D, et al. Isolation and subsequent analysis of murine lamina propria mononuclear cells from colonic tissue. Nat Protoc 2007:2:2307-2311.
44. Aksamit RR, Falk W, Leonard EJ. Chemotaxis by mouse macrophage cell lines. J Immunol 1981;126:2194-2199.

45. Garrett WS, Lord GM, Punit $\mathrm{S}$, et al. Communicable ulcerative colitis induced by T-bet deficiency in the innate immune system. Cell 2007;131:33-45.

46. Fagarasan S, Muramatsu M, Suzuki K, et al. Critical roles of activationinduced cytidine deaminase in the homeostasis of gut flora. Science 2002;298:1424-1427.

47. Rakoff-Nahoum S, Paglino J, Eslami-Varzaneh F, et al. Recognition of commensal microflora by toll-like receptors is required for intestinal homeostasis. Cell 2004;118:229-241.

48. Charrier L, Driss A, Yan $\mathrm{Y}$, et al. hPepT1 mediates bacteria tripeptide fMLP uptake in human monocytes. Lab Invest 2006;86: 490-503.

49. Wojtal KA, Eloranta JJ, Hruz P, et al. Changes in mRNA expression levels of solute carrier transporters in inflammatory bowel disease patients. Drug Metab Dispos 2009;37:1871-1877.

50. Zucchelli M, Torkvist L, Bresso F, et al. PepT1 oligopeptide transporter (SLC15A1) gene polymorphism in inflammatory bowel disease. Inflamm Bowel Dis 2009;15:1562-1569.

51. Yang B, Smith D. Significance of peptide transporter 1 in the intestinal permeability of valacyclovir in wild-type and PepT1 knockout mice. Drug Metab Dispos 2013;41:608-614.

52. Chen HQ, Shen TY, Zhou YK, et al. Lactobacillus plantarum consumption increases PepT1-mediated amino acid absorption by enhancing protein kinase $\mathrm{C}$ activity in spontaneously colitic mice. J Nutr 2010;140:2201-2206.

53. Chen $\mathrm{HQ}$, Yang J, Zhang $M$, et al. Lactobacillus plantarum ameliorates colonic epithelial barrier dysfunction by modulating the apical junctional complex and PepT1 in IL-10 knockout mice. Am J Physiol Gastrointest Liver Physiol 2010;299:G1287-G1297.

54. Hu Y, Smith DE, Ma K, et al. Targeted disruption of peptide transporter Pept1 gene in mice significantly reduces dipeptide absorption in intestine. Mol Pharm 2008;5:1122-1130.

55. Yang XD, Ma JY, Barger MW, et al. Transport and utilization of arginine and arginine-containing peptides by rat alveolar macrophages. Pharm Res 2002;19:825-831.

56. Zaki $\mathrm{MH}$, Lamkanfi $\mathrm{M}$, Kanneganti TD. The Nlrp3 inflammasome: contributions to intestinal homeostasis. Trends Immunol 2011;32 171-179. 